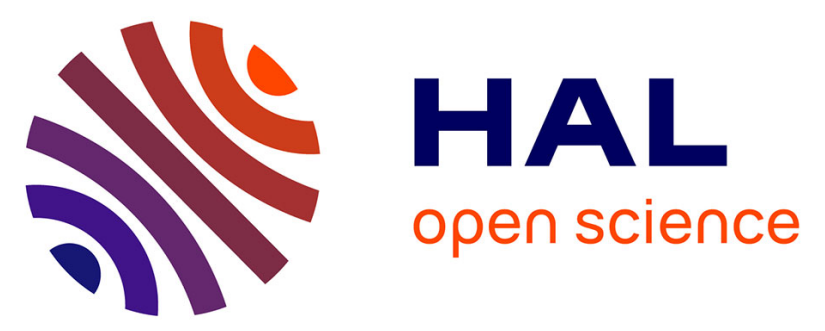

\title{
Using a multicriteria assessment model to evaluate the sustainability of conservation agriculture at the cropping system level in France
}

Damien Craheix, Frédérique Angevin, Thierry Doré, Stéphane de Tourdonnet

\section{- To cite this version:}

Damien Craheix, Frédérique Angevin, Thierry Doré, Stéphane de Tourdonnet. Using a multicriteria assessment model to evaluate the sustainability of conservation agriculture at the cropping system level in France. European Journal of Agronomy, 2016, 76, pp.75-86. 10.1016/j.eja.2016.02.002 . hal01354938

\section{HAL Id: hal-01354938}

https://hal-agroparistech.archives-ouvertes.fr/hal-01354938

Submitted on 22 Aug 2016

HAL is a multi-disciplinary open access archive for the deposit and dissemination of scientific research documents, whether they are published or not. The documents may come from teaching and research institutions in France or abroad, or from public or private research centers.
L'archive ouverte pluridisciplinaire HAL, est destinée au dépôt et à la diffusion de documents scientifiques de niveau recherche, publiés ou non, émanant des établissements d'enseignement et de recherche français ou étrangers, des laboratoires publics ou privés.

\section{(1) (1) $\$$}

Distributed under a Creative Commons Attribution - NonCommercial - NoDerivatives 44.0 
Journal of Agronomy

Elsevier Editorial System(tm) for European

Manuscript Draft

Manuscript Number: EURAGR5154R1

Title: Using a multicriteria assessment model to evaluate the sustainability of conservation agriculture at the cropping system level in France

Article Type: Research paper

Keywords: multicriteria assessment, conservation agriculture, sustainability, direct seeding, cropping system

Corresponding Author: Dr. Frederique Angevin, Phd

Corresponding Author's Institution: INRA

First Author: Damien Craheix

Order of Authors: Damien Craheix; Frederique Angevin, Phd; Thierry Doré; Stéphane de Tourdonnet

http://dx.doi.org/10.1016/j.eja.2016.02.002 


\section{Highlights}

- Sustainability of French cropping systems was assessed with a multicriteria model.

- Systems implemented various levels of conservation agriculture principles.

- Diversified rotations achieved good sustainability scores regardless tillage type.

- Combining reduced tillage and diversified rotation improves environmental impacts.

- Conservation agriculture is not panacea, but it remains a promising strategy. 


\section{Using a multicriteria assessment model to evaluate the sustainability of conservation agriculture at the cropping system level in France}

Craheix D. ${ }^{a}$, Angevin F. ${ }^{a}$, Doré T. ${ }^{\text {b,d }}$, de Tourdonnet S. $^{c}$

aINRA,UAR 1240 Eco-Innov, F-78850 Thiverval-Grignon, France

${ }^{\mathrm{b}}$ AgroParisTech, UMR 211 Agronomie, F-78850 Thiverval-Grignon, France

IINRA, UMR 211 Agronomie, F-78850 Thiverval-Grignon, France

'Montpellier SupAgro - IRC, UMR 951 Innovation, SupAgro-INRA-CIRAD, 2 place Viala,

34060 Montpellier Cedex 1, France

Key words: multicriteria assessment, conservation agriculture, sustainability, direct seeding, cropping system.

Corresponding author: Frederique Angevin (Frederique.Angevin@grignon.inra.fr)

http://dx.doi.org/10.1016/j.eja.2016.02.002 


\section{Abstract}

2 Several international research and development organisations are promoting conservation

3 agriculture in a wide range of contexts. Conservation agriculture is based on a combination

4 of three main principles: (i) minimal or no mechanical soil disturbance; (ii) diversified crop

5 rotations and (iii) permanent soil cover (consisting of a growing crop or a dead mulch of crop

6 residues). However, in the face of the diversity of practices that can be associated with

7 conservation agriculture, of goals assigned to agricultural systems, and pedoclimatic

8 contexts, there is still no empirical evidence about the overall performance of conservation

9 agriculture in France. Global assessments of conservation agriculture, with the full or partial application of its principles and in different contexts, are required to provide a more comprehensive picture of the performance of such systems. We tackled these objectives simultaneously, by evaluating 31 cropping systems with the MASC $\AA$ model (for Multicriteria Assessment of the Sustainability of Cropping Systems). These systems were selected to represent a wide diversity of practices, from ploughed conventional systems to crop sequences based on the full application of conservation agriculture principles. Positive interactions were observed between the key elements of conservation agriculture, resulting in better sustainability performances (particularly in terms of environmental criteria). Nevertheless, the systems most closely respecting the principles of conservation agriculture displayed several weakness, principally of a social or technical nature, in this study. Careful attention should be paid to attenuating these weaknesses. A more detailed analysis of the results also suggested that decreasing soil tillage tends to decrease the overall performance of the system unless associated with a diversification of the crop rotation. 


\section{Introduction}

After the Second World War, increasing yields was a key priority, influencing a shift in European policy towards the promotion of more intensive practices based on mechanisation and high levels of inputs such as energy, fertilisers, and pesticides (Tilman et al., 2002). These policies rapidly lead to increases in yield, but they were counterbalanced by negative environmental impacts, such as groundwater pollution, decreases in soil organic matter content, soil erosion and biodiversity losses. Agriculture is now facing an increasing number of new challenges (e.g. coping with market volatility, resource scarcity and rising demand for raw materials) placing the future of agricultural production systems, ecosystems and the services they provide to society in jeopardy (Tilman et al. 2002)

In response to these challenges, farmers and agronomists have been trying to develop alternative cropping systems. Conservation agriculture $(C A)$ is one of the innovations proposed and is among the most extensively studied new systems developed in recent decades (Scopel et al., 2012). CA systems are based on the following three principles: (i) minimal or no mechanical soil disturbance; (2) diversified crop rotations and (3) permanent soil cover (consisting of a growing crop or a dead mulch of crop residues) (FAO, 2008). Conservation agriculture has been actively promoted by several international research and development organisations, in a wide range of contexts, on the basis of specific field observations and literature reviews (Dumanski et al., 1998; Hobbs et al., 2008; Holland, 2004; Lapar and Pandley, 1999; Lestrelin et al., 2012). CA has already been massively adopted on large-scale mechanised farms, particularly in Australia and Americas but its adoption remains limited in other parts of the world such as Africa and Western Europe (Derpsch et al., 2003; Lahmar, 2010). With the low level of dissemination of CA systems in these regions and the diversity of practices associated with these systems, the effective and global performances of this set of innovations remain unclear and the benefits of CA are increasingly being questioned in the scientific community (Giller et al., 2011; Peigné et al., 
2009; Serpantié et al., 2009). Western European farmers adopting CA approaches often do so without completely respecting all of the principles of CA. This makes it possible for them to broaden the range of options open and to adapt the principles of CA to local conditions. However, it also greatly affects the efficiency and impact of CA systems in the short and long term (Scopel et al., 2012). In the face of the diversity of (i) practices associated with CA, (ii) goals assigned to agricultural systems, and (iii) pedoclimatic contexts, there is still no empirical evidence about the overall performance of CA in the French context (Lhamar, 2010). There is therefore a crucial need to determine the reliability of this innovation with respect to conventional practices (generally involving more intensive soil tillage and less diversified crop rotations), and to clarify the benefits and drawbacks of the full or partial application of conservation agriculture in this context.

To this end, CA systems should be assessed, like other innovations in agriculture, by considering economic, social and environmental aspects, including the expectations of farmers and society at large. Classical approaches based on the optimisation of economic functions, such as cost-benefit analysis, have several drawbacks in this context. These methods are based on quantitative, often monetary variables and are not entirely adequate for the realistic representation of various performances, particularly those relating to social and environmental performances (e.g. difficulty, complexity of implementation, pressure on biodiversity). As already pointed out by other authors, multicriteria evaluation methods suitable for the analysis of qualitative data may be more relevant for the sorting and classification of technical solutions when considering a broad diversity of performances (Figueira et al., 2005, Sadok et al., 2008). Multicriteria decision aid methods, such as the MASC $\AA$ model (Sadok et al., 2009) should therefore be used for such assessments. In this study, using this assessment framework and performed in the context of medium-sized mechanised farms in France, we aimed to determine the extent to which the partial or complete implementation of CA principles affected the overall sustainability of cropping systems. More detailed analyses of the consequences of CA implementation, such as this one, should make it clearer which of the principles of CA contribute most (or not at all) to the 
desired effects in France, and should make it possible to identify ways of improving these cropping systems as well.

\section{Materials and methods}

\subsection{Presentation of the MASC model}

We chose to use the MASC 2.0 (for Multicriteria Assessment of the Sustainability of Cropping Systems) model (Craheix et al., 2012a; Sadok et al., 2009) in this study, for three reasons. Firstly, MASC operates at the level of the cropping system, defined as "a set of management procedures applied to a given, uniformly treated area, which may be a field or a group of fields" (Sebillotte, 1990). The cropping system includes the sequence of crops (rotation) and the various aspects of their management (soil tillage, sowing rate and date, cultivar choice, rates and dates of fertiliser application, crop protection strategy). This small scale is particularly relevant for precise assessments of the negative and positive impacts of the principles of CA, which are closely tied to the field level. Secondly, MASC provides a holistic view of the various performances of the cropping system, because it takes into account the conflicting objectives underlying the economic, social and environmental dimensions of sustainability. Thirdly, this model was also chosen because it can handle various sources of knowledge, managing both quantitative and qualitative information, in the assessment of cropping system performances. MASC was implemented within DEXi computer software (Bohanec, 2014). This software can be used to design qualitative multicriteria models breaking decision problems down into smaller, less complex subproblems formulated in terms of a hierarchy of criteria and aggregation functions.

\section{Through this formalism, MASC conceptualises the sustainability assessment problem by} breaking it down into the three classical dimensions used to define sustainability (social, economic and environmental; Ikerd, 1993, United Nations, 1996). Each dimension 
represents a hierarchy of sustainability objectives organised into a tree-like structure formed by 65 variables (see Figure 1).

\section{Figure 1}

Each variable has a number of qualitative values (or modalities), from 3 to 7 , typically taking the form of a "Low $\rightarrow$ Medium $\rightarrow$ High" progression, with the addition of classes such as "Very Low/Very High" and "Rather low/rather high" in some cases. Variables can be classified as basic criteria (i.e., input variables; 39 variables) and aggregate criteria (i.e., aggregate variables; 26 variables).

Basic criteria relate to elementary concerns of sustainable development (e.g., "Profitability", "Nitrate losses" and "Soil erosion"). These criteria are entered into the model via specific indicators proposed by the model designers. The methods for calculating or evaluating these indicators are detailed in Tables 1 and 2. Six of the 39 indicators proposed are based on direct expertise. The main factors to be taken into account in this expertise are also reported in Tables 1 and 2. Twenty indicators are based on quantitative variables obtained by calculation. For this type of indicator, quantitative values are converted into qualitative variables compatible with the DEXi software through the use of locally defined thresholds. For instance, for the criterion "Profitability", results for the semi-net margin are based on threshold values covering the diversity of the margin observed in a region (e.g. : Very low $\leq$ $€ 200$ /ha $\leq$ Medium to low $\leq € 400 /$ ha $\leq$ Medium to high $\leq € 600 / \mathrm{ha})$. The other 13 indicators are classified as "mixed" as they can deal with both qualitative and quantitative data. These indicators are developed in DEXi software by disaggregating a basic criterion in a subtree, the inputs of which are obtained from a qualitative description of the system or by simple calculation, with the use of threshold values for conversion into qualitative inputs.

In $\mathrm{DEXi}^{\circledR}$, aggregations are performed for each criterion with "utility functions" materialised in tables completed with 'IF-THEN' aggregation rules, such as IF <the criterion "Expectations of 
Society" is "Very low"> AND IF <the criterion "Expectations of Farmers" is "Low to medium"> THEN <the aggregate criterion "Social Sustainability" is "Very low"> (see the example in Figure 1). Each utility function can be filled in manually or semi-automatically, based on the weights applied to each criterion. All the utility functions were included in the model by the designers and can be considered to provide a well-balanced perception of sustainability, given that the weights are generally evenly distributed between criteria. However, users can modify these functions, to adapt the model to their local context and preferences (Craheix et al., 2012b). In this study, we performed assessments with the weights assigned by the designers of the MASC model (Figure 2). Using the aggregation devices of the MASC model, it is possible to rank the cropping systems according to their overall sustainability and its three dimensions (i.e. economic, social, and environmental). In DEXi software, an ordinal scale is associated with each qualitative scale (e.g. very low $=1$, low $=2, \ldots$, very high $=5$ ). The mean and standard deviation of the ordinal scales can therefore be calculated and used to represent the results.

Relative to the first version published by Sadok et al. (2009), the second version of the model, as used here, presents several improvements that helped to delimit the outline of this assessment. The designers made use of feedback from the initial users (Craheix et al., 2012c) and included new criteria in the tree, to ensure that levels such as the production chain and society were better encompassed in the economic and social dimensions (e.g.: "Supply of raw materials", "New supply chain emergence" , "Sanitary quality"). In accordance with a previous adaptation of MASC 1.0 to organic farming systems (Colomb et al., 2012), a new branch, "Long-term productive capacity", was inserted into the economic dimension of MASC 2.0. This modification makes agronomic viability a key determinant of the economic sustainability of innovative cropping systems, by taking into account both soil fertility and the control of pests and weeds. Finally, based on the DEXiPM model (Pelzer et al., 2012), the "Biodiversity Conservation" branch of the environmental dimension was profoundly modified to restrict assessment to the less mobile groups of organisms, which are heavily dependent 
on crop interventions at the field scale (i.e. flora, soil macrofauna, flying insects and soil micro-organisms). These new criteria were inserted while taking advantage of the sensitivity analysis performed on the MASC model (Carpani et al., 2012; Bergez, 2013). They were designed to both maintain sensitivity of the model and to avoid structural effects leading to involuntarily increase of the weight of some criteria.

Finally, the aptness of the model for evaluating the performances of CA systems was evaluated by following a three-step procedure (Bockstaller et al. 2009; 2003) based on: (i) an evaluation of the structure of the model (ii) an evaluation of the outputs generated by the model and (iii) an evaluation of the usefulness of the model in diverse situations of use. At each of these stages, we combined constructive criticism from a broad panel of experts and stakeholders involved in this study (researchers, advisors, farmers) with information published in peer-reviewed articles. This work led to a number of improvements that were directly integrated into the second version of the MASC model used in this study.

\subsection{Description of the cropping systems evaluated}

In this study, 31 cropping systems were selected from both farm-based and experimental station sites, to represent a wide diversity of practices, from ploughed systems with short crop rotations to systems in which the principles of CA were fully applied (Table 3).

The description of these cropping systems was based on a list of farming practices and the yields obtained for each crop, through a combination of recorded data and expertise. The cropping systems were collected from six different regions of France (i.e. Haute-Normandie, Champagne-Ardenne, Rhône-Alpes, Centre, Aquitaine, Franche-Comté), so as to take into account various pedoclimatic contexts. In terms of economic data, we considered, for all the cropping systems assessed, the same purchase prices for inputs and selling prices for crops, based on the average over the preceding five years (i.e. 2008-2013). 
We defined six types of cropping system on the basis of the extent to which the principles of CA were applied (Figure 2). These types were defined in terms of the intensity of tillage and the diversity of crops in the rotation. The permanence of soil cover, the third pillar of CA, was taken into account indirectly in this typology, by combining the information for the first two pillars. The intensity of tillage was assessed by assigning cropping systems to one of three classes: (i) ploughed cropping systems (PL), in which ploughing was performed at least one year in three in the crop rotation, (ii) cropping systems based on reduced tillage (RT), including both low-frequency ploughing (less than one year in three) and regular noninversion tillage (i.e. chisel plough, disc plough, rotary harrow) and (iii) direct seeding cropping systems (DS) with no ploughing and a very low frequency of tillage or of shallow interventions (to a depth of no more than $5 \mathrm{~cm}$ ). Cropping systems were assigned to one of two groups for crop rotation, to distinguish between rotations with high and low levels of diversification. These two groups were defined on the basis of rotation length, the presence of cover crops, the diversity of crop families and the presence of different and distinct sowing dates in the crop sequence.

\section{Figure 1}

\section{Results}

\subsection{Analysis of the main sustainability criteria scores}

The overall sustainability scores of the various cropping system types (Figure 3) were between 3 ("rather low") and 6 ("high"). Systems based on diversified rotations had the best overall sustainability scores, with a mean score of more than 5 ("rather high"), regardless of the tillage conditions. Diversification of the rotation thus had a stronger positive effect than decreasing soil tillage on the overall sustainability score obtained with MASC. Conversely, decreasing soil tillage only had a marked impact on the results in systems with low levels of crop diversification. In this situation (LC), only systems with superficial soil tillage only (RTLC) had overall sustainability scores above four ("medium"). Systems combining direct 
seeding and a low diversification of the rotation had lower overall sustainability scores $(3 / 7$, "rather low"), close to those of conventional systems (PL-LC).

\section{Figure 3}

We then used the results for the three underlying dimensions of sustainability to refine our analysis. For the economic dimension of sustainability, the conventional system (PL-LC type) had a mean score of 3 ("medium"), but all the other types had mean scores of between 4 (i.e. "rather high") and 5 (i.e. "high").

For the social dimension of sustainability, the DS type presented the worst results, particularly for low levels of diversification of the crop rotation. By contrast, the PL and RT types had better mean scores, between 4 (i.e. "high") and 5 (i.e. "very high").

For the environmental dimension of sustainability, there was clearly a positive interaction between reducing tillage and diversifying crop rotations. For environmental sustainability, none of the cropping systems based on short and less diversified crop rotations had a score of 3 ("medium") or more. Environmental performance was more variable for reduced tillage (RT) systems than for the other types of system.

\subsection{Analysis of scores for basic criteria}

The results of each dimension were too synthetic to account for the overall ranking on their own. A more detailed analysis of the basic criteria was therefore required to identify the major strengths and weaknesses of the cropping systems studied. Only the results for the principal basic criteria discriminating between the systems evaluated in terms of performance are presented here.

More detailed results for the economic dimension (Figure 4) indicated that systems with low frequencies and shallow depths of soil tillage (i.e. the RT and DS types) were at least as profitable as ploughed systems. These systems obtained better results for the "economic efficiency" criterion, reflecting a lower economic dependence on inputs (e.g. fuel, fertiliser, pesticides). Nevertheless, reduced tillage systems and systems with only very superficial 
tillage operations had worse results than ploughed systems for the criteria "weed control" and "control of insect pests and diseases". In parallel, systems based on long diversified rotations, particularly those including legumes (as the principal or cover crop) were generally more profitable and had a higher economic efficiency than less diversified systems. These systems also had better scores for the criteria "weed control" and "sanitary quality" (estimating the sanitary risk associated with the presence of mycotoxins). However, systems combining a diversified crop rotation with reduced or very superficial soil tillage did not obtain better results than other systems for the indicator "control of insect pests and diseases".

\section{Figure 4}

For the social dimension (Figure 5), we observed that reduced tillage and direct seeding systems (i.e. RT and SD) obtained better scores for the criterion "work overload" than ploughed systems. This criterion reflects the capacity of a system to decrease the number of hours of work required at busy times (e.g. sowing, weed control and harvesting). However, these systems were penalised for their small contribution to employment, due to the small number of hours of work required per hectare and per year. Our results indicated that the lower intensity of soil tillage in these systems also had a negative impact on the criteria "health risk for farmers" due to the large number of applications of phytosanitary products. The results for the "system complexity" criterion also reflected the greater difficulty for farmers to control the need for interventions in these cropping systems.

\section{Figure 5}

However, the deleterious effects of direct seeding systems were nevertheless smaller in more diversified crop rotations (DS-HC in Figure 3). In these rotations, the presence of a greater diversity of main and cover crops seemed to have a positive impact on the criterion "contribution to local employment", by increasing the mean number of hours of work per year, and on the criterion "pesticide use-related health risk", due to smaller numbers of pesticide 
applications (Figure 4). The social impact of a greater diversity of crops in the rotation was nevertheless essentially negative for the criteria "system complexity" and "technical and economic monitoring time". Indeed, the main and cover crops in these rotations, which differed from those present in less diversified rotations, were often a bit more difficult to manage (e.g. insertion and destruction of new cover crops) and the larger number of different crops also increases the time that the farmer must spend updating his technical and economic knowledge about his crops.

For the environmental dimension, cropping systems with long and diversified crop rotations $(\mathrm{HC})$ obtained the best scores, particularly when combined with reduced tillage (RT) or direct seeding practices (DS) (Figure 3). As indicated by the more detailed results in Figure 6, these systems had better results than ploughed systems for the criteria "soil macrofauna conservation", "soil erosion control" and "soil organic matter content control". However, their performances were similar to those of ploughed systems for the criterion "energy consumption" and "control of $\mathrm{NO}_{3}$ losses".

Diversified rotations performed better than less diversified systems for the criterion "energy consumption". Thus, whereas reducing tillage decreases direct fuel energy consumption, diversifying the rotation, particularly if legumes are included, makes it possible to decrease more strongly the input of mineral nitrogen, a major contributor to the indirect consumption of energy. In this respect, SD-LC systems had the worst results, due to the use of larger amounts of synthetic nitrogen fertiliser to nourish the higher proportion of cash crops in these cropping systems. The diversification of rotations, particularly if cover crops are included, was mildly advantageous for the criteria "soil erosion control" and "control of $\mathrm{NO}_{3}$ losses". The results obtained for the criteria "organic matter content control" and "soil macrofauna conservation" differed little between rotations as a function of the level of diversification.

\section{Discussion}




\subsection{Variability of the results}

The results obtained for the aggregate and basic criteria revealed a relatively high level of variability within each of the cropping system types evaluated. This variability was no greater for conventional agriculture systems than for systems following the principles of CA more closely. This variability was sufficiently large for better overall sustainability scores to be obtained, in some situations, by ploughed systems or systems based on short rotations with low levels of diversification than by systems adhering more closely to the principles of CA. This high degree of variability highlights the importance of not focusing too heavily on the determinants used to construct this typology (intensity of soil tillage and diversification of crops in the rotation) at the expense of the broad range of technical options available in each cropping system type (e.g. choice of material, intervention dates, crop varieties).

It should also be noted that soil tillage and the diversity of crops included in the rotation are not the only determinants accounting for the performance of cropping systems, in terms of basic and aggregate indices. Many other farming operations, such as the level of use of fertilisers and pesticides, and site-specific factors, including soil characteristics and local climatic conditions, can account for differences in performance within a given cropping system type (Erenstein, 2003; Knowler and Bradshaw, 2007). More precise studies are required to unravel the multiple complex interactions between management factors and to determine the precise locations and conditions most suitable for CA.

It should also be borne in mind that differences in performance between years were not taken into account in this study, because the evaluations are based on an "average description" of the systems and their climatic and economic environments. In general, few scientific studies take into account the interannual variability of economic, social and environmental performances in CA systems. There is nevertheless considerable variability in performance, particularly during the transition phase, which largely determines the attractiveness of CA to farmers. In this respect, as pointed out by Giller et al. (2011; 2009), a more precise analysis of the robustness of performances in CA is a key issue that should be 
addressed by researchers, to determine, in particular, the effect of climatic variability on these systems.

\subsection{Output evaluation and the main lessons learned}

As previously stated and recommended by Bockstaller et al. $(2009,2003)$, the a priori evaluation of the structure of the model for its use in conservation agriculture was followed by an a posteriori analysis of the results produced. Due to the immeasurable nature of sustainability and the number of indicators used to evaluate it, we were unable to perform an evaluation based on comparisons with measurements or direct observations in the field. The pertinence of the results will therefore be assessed here by comparison with published results from scientific studies focusing on the performances of conservation agriculture in similar contexts. We avoided tautological validation by paying particular attention to avoiding the citation of articles used to construct or improve the structure of the indicators.

There is little scientific evidence for an economic impact of CA in the European context. Nevertheless, according to Lahmar (2010) and Scopel et al. (2012), cost savings in terms of fuel, labour and machinery remain the most important economic features of conservation agriculture, driving its adoption in Europe. These observations are consistent with the results obtained for the "economic efficiency" indicator. According to the same authors, the impact on profitability of the adoption of the principles of CA remains difficult to estimate due to the diversity of contexts and practices. Nevertheless, according to Scopel et al. (2012), these practices generally appear to be profitable when they are technically well mastered. This is an important aspect, because decreasing soil tillage tends to increase the risks of infestation with weeds (Debaeke and Orlando 1994) and necrotrophic parasites, which may survive and develop on crop residues at the soil surface (Glen and Symondson, 2003, Kreye, 2004). These observations are consistent with the results provided by MASC in this study, indicating that this short-term economic benefit could be counterbalanced by a yield decrease, due to 
341 higher levels of infestation with weeds, pests and diseases or additional costs relating to their

342 control. According to Lahmar (2010), such problems may lead some European farmers to

343 prefer specific crops that are more easily managed with CA or to return to conventional 344 practices. However, these outcomes go against the empirical experience of some of the farmers and advisors involved in this study, who reported that such systems were actually less susceptible to pests, diseases and weeds because the lower level of soil disturbance results in a greater biodiversity of natural enemies, and well adapted crop rotations prevent the build-up of pests and weeds. These observations are consistent with several other scientific findings (Derpsch et al., 2003; Palm et al., 2014; Sturz et al., 1997). Thus, although the results of this study highlight some of the weaknesses of CA cropping systems, they also identify a weakness of the MASC model, in terms of its ability to estimate the agronomic effects of biodiversity from a description of the practices employed and the context. As suggested by Bell and Morse (2008), the designers of the MASC model built their indicators from the available scientific knowledge, whilst trying to keep their use relatively simple. This probably led to the retention of rules that are too generalised and that do not precisely cover the diversity of pedoclimatic situations and techniques observed in this study. As pointed out by Médiène et al. (2011), we still have little scientific information concerning the responses of biological process to agricultural practices in a given pedoclimatic context. Thus, as highlighted by Palm et al. (2014), the complex trade-off between the services provided and the deleterious effects caused by the greater biodiversity resulting from reduced tillage and diversification of the crop rotation remains unclear. Specific studies on this topic are therefore required to identify the determinants involved and to make it possible to propose more accurate indicators.

Reduced and no tillage systems had poorer performances for the social dimensions of the model than other cropping systems with more intensive tillage. DS cropping systems performed less well than other systems for the criteria "system complexity", "health risk of pesticide use" and "contribution to local employment". These results are basically consistent 
with most of the published results concerning the performances of CA. Overall, CA is often seen as a complex set of interrelated practices that typically requires several rounds of adaptation to become fully viable. It involves learning on the part of the farmer, local adaptation, and breaking with a long-standing tradition of soil tillage and the removal of crop residues (Giller et al., 2011; Lahmar, 2010).

The lack of tillage in SD cropping systems, particularly those with a low level of crop diversification in the rotation, often results in the proliferation of weeds, necessitating the more frequent application of larger amounts of herbicide by farm workers (Chapelle-Barry, 2008), resulting in the exposure of these workers to a higher risk of toxicity. Moreover, the overall decrease in working time associated with reduced tillage systems, which is generally attractive for farmers, is considered to be a negative aspect in the MASC model, because it may lead to a decrease in agricultural employment in the area. This criterion draws attention to one of the potential risks of the widespread adoption of CA. However, the accuracy of this assessment is restricted to the information available at the field scale. According to Lahmar (2010), the labour saved by not tilling the soil could be diverted to other agricultural or nonagricultural activities on a larger scale. This highlights how the "granularity" of the spatiotemporal scales of the cropping system is less relevant for addressing issues that are partly dependent on higher levels of organisation, such as the farm or an agricultural region (e.g. indicators "work overload" and "emergence of a new supply chain"). The results for this criterion should therefore be interpreted with caution, focusing purely on the contribution of the cropping system, everything else being equal.

The main benefits in terms of the environmental dimension of cropping systems closely following CA principles (i.e. RT-HC and SD-HC) are consistent with the observations of several authors in temperate regions in Europe. Reduced and no tillage systems, particularly if the crop residues are left on the soil surface, tend to lead to an increase in carbon sequestration within the soil. In terms of biodiversity conservation, positive effects of CA on the soil macrofauna, flora and micro-organisms have also been reported by many authors 
(Debaeke and Orlando, 1994; Emmerling, 2001; Peigné et al., 2009; Vian et al., 2009). CA has also been reported to limit soil erosion, by improving water infiltration, due to the higher soil organic matter content and the presence of crop residues at the soil surface. The larger population of earthworms in conservation tillage conditions is also known to favour water flow and infiltration (Frielinghaus, 2007). Decreasing the frequency of tillage decreases the direct consumption of fossil energy, but diversifying the rotation by introducing legumes appears to be a more efficient way of decreasing energy consumption. The introduction of legumes into the rotation makes it possible to decrease the total amount of nitrogen fertiliser applied. Several authors have reported a strong correlation between the total energy consumption of cropping systems and the amount of nitrogen fertiliser applied.

The MASC model provided an overview of the performances of cropping systems as a function of the degree to which CA principles were applied, within the French context. As suggested by Giller et al. (2009) the assessment of a large number of cropping systems and the analysis of their performances according to whether the principles of CA were applied, fully, partially or not at all, make it easy to determine which of these principles contribute to the desired effect. The results of this study suggest that decreasing, or even abolishing tillage, one of the major symbolic pillars of CA systems, is not the most effective way to increase the overall sustainability of cropping systems. Direct seeding systems with short and undiversified rotations gave the worst sustainability results, with scores slightly lower than those for conventional systems. Conversely, the adoption of long diversified crop rotations, regardless of the soil tillage conditions, appeared to be essential for attaining a high level of overall sustainability. Therefore, rotations including diverse cash and cover crops are an essential element of CA systems, as they provide an effective way to manage pests and weeds in the absence of soil tillage. The promotion of greater biodiversity at the field level favours the better use of natural resources, a more regular distribution of labour and more diversified farm incomes (Calegari et al., 2008; Médiène et al., 2011; Scopel et al., 
2012). Therefore, consistent with the assertions of most authors (Derpsch et al., 2003;

423 Erenstein, 2003; FAO, 2008; Hobbs, 2007; Scopel et al., 2012), CA is an "holistic" package

424 that works well only when all three pillars are applied simultaneously.

\subsection{End-use evaluation of the MASC model and precautions for use}

This study provides a form of evaluation of the model in terms of its utility in the situation of application. According to Bockstaller et al. (2003), an assessment model may lack usefulness for several reasons: a target of great relevance to potential users may have been left out, some data required for calculations may not be available or the outputs of the assessment may be incomprehensible or illegible.

The positive feedback received from several of the stakeholders (e.g. researchers, extension workers and farmers) involved in this study suggests that the major preoccupations of users were adequately taken into account (Craheix et al., 2012b; Craheix et al., 2012c). Thus, the holistic approach of the MASC model, based on a sustainability assessment, provides a suitable overview of the performance of cropping systems, by taking into account simultaneously (i) the multiple objectives of the economic, social and environmental dimensions; ii) various time scales, ranging from the short term to the long term and (iii) the concerns raised at various levels, including the expectations of farmers and of society as a whole. However, although this assessment framework may be seen as very integrative and objective, caution is required in the use of such models and the interpretation of the results obtained, due to the underlying subjectivity inherent in the criteria chosen and their aggregation (Bell and Morse, 2008). Designers try to counterbalance this apparent binding framework by encouraging debate with end-users when interpreting results. Designers have also introduced flexibility by allowing users to modify both the method by which basic criteria are assessed (i.e. choice of indicators) and the weights assigned to the various criteria, so as to integrate their own preferences and visions of sustainable development into the parameter settings. Interesting results have already been reported in France, where the MASC model was used to get farmers involved in the evaluation of their cropping systems through the 
discussion and modification of parameter settings (Craheix et al., 2012b). In this study

450

451

452

453

454 cropping systems were ranked with the default version of MASC, based on a balanced perception of sustainability. It should be borne in mind that the rankings would be probably different if the weights were modified (e.g. by increasing the relative weight of the environmental dimension for instance). Therefore, according to the designers of the MASC model and as suggested by Bell and Morse (2008), the development and use of the multicriteria assessment method for sustainability requires maximum transparency and flexibility and should never be limited to the interpretation of aggregate results alone.

Regarding the ease of use of the model in terms of the availability of the data required and the comprehensibility of the outputs, the ability of MASC to deal with qualitative information appeared very useful in these real-use situations. Firstly, as noted above, processing qualitative information makes it possible to use quantitative values by simply using thresholds to render them qualitative. This flexibility makes it possible for the MASC model to combine various data, such as simple measurements (e.g. yields), calculated data (e.g. semi-net margin) and empirical knowledge (e.g. physical difficulties of crop interventions) into the indicators, so as to make the best use of commonly available information. Secondly, it makes it possible to integrate the decision-maker's own views (concerning the "system complexity" criterion, for example) into the model, as these views are not necessarily expressed through formal, quantitative models. Finally, regarding the legibility of the outputs, as suggested by Munda et al. (2005), qualitative and linguistic forms (such as "low", "medium" or " high") appeared to be well understood by the stakeholders concerned as natural representations of human judgments and cognitive observations. Furthermore, qualitative decision rule-based methods are considered relevant for non-compensatory decision strategies involving the aggregation of results for different criteria (Ma, 2006), making it easier to tackle the issues of a lack of comparability and immeasurability that often underlie the dimensions of sustainability in agricultural systems (Sadok et al., 2008). Nevertheless, the homogenisation of calculated variables into qualitative variables, which are 
by nature discrete, together with the classification of the systems studied into large classes, may lead to marked differences in judgement concerning performances that are actually relatively similar. The choice of the thresholds separating qualitative classes for particular criteria was adapted here so as to minimise this risk.

\section{Conclusion}

Assessing the relevance of innovations, such as CA, remains a difficult exercise, because several objectives, some of which conflict, and criteria of different natures must be taken into account. Multicriteria decision aid models, such as MASC $^{\circledR}$, have been developed to overcome these apparent difficulties by providing a holistic approach to the problem based on an assessment of the sustainability of cropping systems. The use of this model in the French context provides a more comprehensive assessment of the various performances of $\mathrm{CA}$, through comparisons with conventional systems and intermediate systems in which the principles of CA are applied only partially. The results obtained thus provide a better perception of the overall relevance of $\mathrm{CA}$ and improve our understanding of the principles contributing to the desired effect.

Firstly, the results of this study indicate that CA is a promising alternative to conventional practices that can improve the sustainability of cropping systems in France, provided that it is applied in full. Secondly, a detailed analysis of intermediate systems partially applying the principles of CA revealed that there was a positive interaction between the reduction of tillage and the diversification of the crop rotation for the environmental dimension. However, diversification of the crop rotation was found to be the best way to increase the overall sustainability of cropping systems. Cropping systems involving diversified rotations achieved good results, regardless of the tillage regime, whereas direct seeding-based systems not coupled with a diversified rotation had the lowest sustainability scores. Thus, decreasing soil 
501 tillage appeared to be less effective in this study than diversifying the crop rotation, and

502 should therefore not be applied in isolation.

503 According to these findings, CA, as a holistic package, is an interesting way to improve the

504 sustainability of agricultural systems in the French context. However, when this strategy is 505 preferred, the social and agronomic difficulties reported in this study should be taken into

506

507

508

509

510

511

Bell, S., Morse, S., 2008. Sustainability Indicators: Measuring the Immeasurable? Second 525

account. A gradual transition from ploughed conventional systems towards CA systems should be encouraged, with the early consideration of a specific cover crop management strategy involving crops from different families. Finally, the results of this study require confirmation and completion with field measurements, for a larger number of more diverse cropping systems, with the evaluation of CA over larger scales (the farm and regional scales). Furthermore, the validity of our findings could not be easily extended to areas where AC is more widespread and where the conditions of soil and climate, including drought intensity and frequency, are different from those of Western Europe.

\section{Acknowlegements}

The authors would like to thank Ms N. Landé (CETIOM), J. Peigné (ISARA), N. Torrès (Vivescia), M.M. F Hirissou (Chambre d'Agriculture de la Dordogne) and B. Omon (Chambre d'Agriculture de l'Eure) for providing them with data for this analysis.

This work was carried out with the financial support of the ANR-Agence Nationale de la Recherche (The French National Research Agency) under the Programme national de recherches écoSystèmes, Territoires, Ressources vivantes et agricultures (Systerra) project ANR-08-STRA-10, PEPITES.

\section{References} ed. Earthscan, London, Stering, VA. 
526 Bergez, J.É., 2013. Using a genetic algorithm to define worst-best and best-worst options of

527 a DEXi-type model: Application to the MASC model of cropping-system sustainability.

528 Comput. Electron. Agric. 90, 93-98. doi:10.1016/j.compag.2012.08.010

529 Bohanec, M., 2014. DEXi: Program for multicriteria decision making, User's manual, Version 530 4.0. IJS Report DP-113401134011340, Jožef Stefan Institute, Ljubljana.

531 http://kt.ijs.si/MarkoBohanec/pub/DEXiManual400DEXiManual400DEXiManual400.pdf

532 Bockstaller, C., Girardin, P., van der Werf, H.M., 1997. Use of agro-ecological indicators for 533 the evaluation of farming systems. Eur. J. Agron 7, 261-270. doi:10.1016/S1161$534 \quad \underline{0301(97) 00041-5}$

535 Bockstaller, C., Girardin, P., 2003. How to validate environmental indicators. Agric. Syst. 76, 536 639-653. doi:10.1016/S0308-521X(02)00053-7

537 Bockstaller, C., Guichard, L., Keichinger, O., Girardin, P., Galan, M.-B., Gaillard, G., 2009.

538 Comparison of methods to assess the sustainability of agricultural systems. A review. Agron.

539 Sustain. Dev. 29, 223-235. doi:10.1051/agro:2008058

540 Calegari, A., Hargrove, W. L., Dos Santos Rheinheimer, D., Ralisch, R., Tessier, D., de 541 Tourdonnet, S., de Fatima Guimaraes, M., 2008. Impact of long-term no-tillage and cropping 542 system management on soil organic carbon in an oxisol: a model for sustainability. Agron. J. 543 100, 1013-1019. doi:10.2134/agronj2007.0121

544 Carpani, M., Bergez, J.É., Monod, H., 2012. Sensitivity analysis of a hierarchical qualitative 545 model for sustainability assessment of cropping systems. Environ. Model. Softw. 27-28, 15546 22. doi:10.1016/j.envsoft.2011.10.002

547 Chapelle-Barry, C., 2008. Dans le sillon du non-labour. Agreste Primeur, 207. 548 http://www.agreste.agriculture.gouv.fr//MG/pdf/primeur207.pdf (accessed 01.04.14).

549 Colomb, B., Carof, M., Aveline, A., Bergez, J.É., 2012. Stockless organic farming: strengths 550 and weaknesses evidenced by a multicriteria sustainability assessment model. Agron. 551 Sustain. Dev. 33, 593-608. doi: 10.1007/s13593-012-0126-5

552 Craheix, D., Angevin, F., Bergez, J.É., Bockstaller, C., Colomb, B., Guichard, L., Reau, R., 553 Doré, T., 2012a. MASC 2.0, un outil d'évaluation multicritère pour estimer la contribution des 554 systèmes de culture au développement durable. Innov. Agron. 20, 35-48. 555 http://www.inra.fr/ciag/revue/volume 20 juillet 2012 (accessed 15.10.12).

556 Craheix, D., Angevin, F., Bergez, J.É., Bockstaller, C., Colomb, B., Guichard, L., Reau, R., 557 Omon B., Doré, T., 2012b Multicriteria assessment of the sustainability of cropping systems: 558 A case study of farmer involvement using the MASC model, in: Proceedings of the 10th 559 European IFSA Symposium, 1-4 July 2012, Aarhus, Denmark. 
561 Craheix, D., Angevin, F., Reau, R., Bergez, J. É., Bockstaller, C., Doré, T., Guichard, L., 562 Colomb, B., 2012c. MASC, a model to assess the sustainability of cropping systems: Taking 563 advantage of feedback from first users, in: Proceedings of the XII ${ }^{\text {th }}$ congress of the European 564 Society for Agronomy, 20-24 August 2012, Helsinki, Finland. 282-283.

565 Debaeke, P., Orlando, D., 1994. Simplification du travail du sol et évolution de la flore 566 adventice : conséquences pour le désherbage a l'échelle de la rotation in: INRA (Eds.), 567 Simplification du travail du sol, Colloques de l'INRA (65), Paris, pp. 35-62.

568 Derpsch, R., 2003. Conservation Tillage, No-Tillage and Related Technologies, in: García569 Torres, L., Benites, J., Martínez-Vilela, A., Holgado-Cabrera, A. (Eds.), Conservation 570 Agriculture. Springer Netherlands, pp. 181-190.

571 Dumanski, J., Pettapiece, W.W., McGregor, R.J., 1998. Relevance of scale-dependent 572 approaches for integrating biophysical and socio-economic information and development of 573 agroecological indicators. Nutr. Cycl. Agroecosyst. 50, 13-22.

574 Emmerling, C., 2001. Response of earthworm communities to different types of soil tillage. 575 Appl. Soil Ecol. 17, 91-96. doi:10.1016/S0929-1393(00)00132-3

576 Erenstein, O., 2003. Smallholder conservation farming in the tropics and sub-tropics: a guide 577 to the development and dissemination of mulching with crop residues and cover crops. Agric.

578 Ecosyst. Environ. 100, 17-37. doi:10.1016/S0167-8809(03)00150-6

579 Figueira, J., Greco, S., Ehrgott, M., 2005. (Eds.) Multiple Criteria Decision Analysis: State of 580 the Art Surveys, Springer-Verlag, New York.

581 Frielinghaus, M., 2007. Soil Erosion and Pesticide Translocation Control, in: Pimentel, D. 582 (Ed.) Encyclopedia of Pest Management. Taylor and Francis, New York, pp. 777-780.

583 FAO, 2008. Investing in Sustainable Agricultural Intensification. The Role of Conservation 584 Agriculture. A Framework for Action. Food and Agriculture Organisation of the United 585 Nations, Rome. http://www.fao.org/ag/ca/doc/proposed framework.pdf

586 Glen, D.M. and Sysmondson, W.O.C. 2003. Influence of soil tillage on slugs and their natural 587 enemies. In: El Titi, A. (Ed.), Soil tillage in Agroecosystems, CRC Press, Boca Raton, FL, pp. 588 207-227.

589 Giller, K.E., Witter, E., Corbeels, M., Tittonell, P., 2009. Conservation agriculture and 590 smallholder farming in Africa: The heretics' view. Field Crops Res.114, 23-34. 591 doi:10.1016/j.fcr.2009.06.017

592 Giller, K.E., Corbeels, M., Nyamangara, J., Triomphe, B., Affholder, F., Scopel, E., Tittonell, 
P., 2011. A research agenda to explore the role of conservation agriculture in African smallholder farming systems. Field Crops Res. 124, 468-472. doi:10.1016/j.fcr.2011.04.010

Gravesen, L., 2003. The Treatment frequency index - An Indicator for pesticide use and dependency as well as overall load on the environment. In: Proceedings of the PURE Conference, Reducing pesticide dependency in Europe to protect health, environment and biodiversity, 20 November 2003, Copenhagen, Denmark, 28-30. http://paneurope.info/old/Archive/conferences/pure2003.pdf

Hobbs, P.R., 2007. Conservation agriculture: what is it and why is it important for future sustainable food production? J. Agric. Sci. 145. 127-137. http://dx.doi.org/10.1017/S0021859607006892

Hobbs, P.R., Sayre, K., Gupta, R., 2008. The role of conservation agriculture in sustainable agriculture. Phil. Trans. R. Soc. B. 363, 543-555.

Holland, J.M., 2004. The environmental consequences of adopting conservation tillage in Europe: reviewing the evidence. Agric. Ecosyst. Environ. 103, 1-25. doi:10.1016/j.agee.2003.12.018

Ikerd, J.E., 1993. The need for a system approach to sustainable agriculture. Agric. Ecosyst. Environ.46, 147-160. doi:10.1016/0167-8809(93)90020-P

Knowler, D., Bradshaw, B., 2007. Farmers' adoption of conservation agriculture: A review and synthesis of recent research. Food Policy 32, 25-48. doi:10.1016/i.foodpol.2006.01.003

Kreye H., 2004. Effects of conservation tillage on harmful organisms and yield of oilseed rape. Bulletin OILB/SROP 27, $25-29$.

Lahmar, R., 2010. Adoption of conservation agriculture in Europe: Lessons of the KASSA project. Land Use Policy 27, 4-10. doi: 10.1016/..landusepol.2008.02.001

Lapar, M.L.A., Pandey, S., 1999. Adoption of soil conservation: the case of the Philippine uplands. Agric. Econ. 21, 241-256.

Lestrelin, G., Quoc, H.T., Jullien, F., Rattanatray, B., Khamxaykhay, C., Tivet, F., 2012. Conservation agriculture in Laos: diffusion and determinants for adoption of direct seeding mulch-based cropping systems in smallholder agriculture. Renew. Agric. Food Syst. 27, 8192. http://dx.doi.org/10.1017/S174217051100055X

Ma, L., 2006. Knowledge representation under Inherent uncertainty in a multi-agent system for land use planning, Ph.D. Thesis, Eindhoven University of Technology, Eindhoven, The Netherlands, 164p.

Médiène, S., Valantin-Morison, M., Sarthou, J.-P., Tourdonnet, S., Gosme, M., Bertrand, M., 
626 Roger-Estrade, J., Aubertot, J.-N., Rusch, A., Motisi, N., Pelosi, C., Doré, T., 2011. 627 Agroecosystem management and biotic interactions: a review. Agron. Sustain. Dev. 31, 491628 514. doi:10.1007/s13593-011-0009-1

629 Munda, G., 2005. Multiple Criteria Decision Analysis and Sustainable Development, in: 630 Greco, S. (Ed.), Multiple Criteria Decision Analysis: State of the Art Surveys, Springer New 631 York, pp. 953-986.

632 Palm, C., Blanco-Canqui, H., DeClerck, F., Gatere, L., Grace, P., 2014. Conservation 633 agriculture and ecosystem services: An overview. Agric. Ecosyst. Environ. 187, 87-105.

634 Peigné, J., Cannavacciuolo, M., Gautronneau, Y., Aveline, A., Giteau, J.L., Cluzeau, D., 635 2009. Earthworm populations under different tillage systems in organic farming. Soil Tillage 636 Res. 104, 207-214. doi:10.1016/j.still.2009.02.011

637 Pelzer, E., Fortino, G., Bockstaller, C., Angevin, F., Lamine, C., Moonen, C., Vasileiadis, V., 638 Guérin, D., Guichard, L., Reau, R., Messéan, A., 2012. Assessing innovative cropping 639 systems with DEXiPM, a qualitative multicriteria assessment tool derived from DEXi. Ecol. 640 Indic. 18, 171-182. doi:10.1016/j.ecolind.2011.11.019

641 Sadok, W., Angevin, F., Bergez, J.-É., Bockstaller, C., Colomb, B., Guichard, L., Reau, R., 642 Doré, T., 2008. Ex ante assessment of the sustainability of alternative cropping systems: 643 implications for using multicriteria decision-aid methods. A review. Agron. Sustain. Dev. 28, 644 163-174. doi:10.1051/agro:2007043

645 Sadok, W., Angevin, F., Bergez, J.-É, Bockstaller, C., Colomb, B., Guichard, L., Reau, R., 646 Messéan, A., Doré, T., 2009. MASC, a qualitative multi-attribute decision model for ex ante 647 assessment of the sustainability of cropping systems. Agron. Sustain. Dev. 29, 447-461. doi $648 \quad 10.1051 /$ agro/2009006

649 Scopel, E., Triomphe, B., Affholder, F., Silva, F.A.M., Corbeels, M., Xavier, J.H.V., Lahmar, 650 R., Recous, S., Bernoux, M., Blanchart, E., Mendes, I., Tourdonnet, S., 2013. Conservation 651 agriculture cropping systems in temperate and tropical conditions, performances and 652 impacts. Agron. Sustain. Dev. 33, 113-130. doi: 10.1007/s13593-012-0106-9

653 Sebillotte, M., 1990. Système de culture, un concept opératoire pour les agronomes, in: 654 Lacombe, L., Picard, D. (Eds.), Un Point Sur Les Systèmes de Culture. INRA Éditions Paris, 655 pp. 165-190.

656 Serpantié, G., 2009. L'agriculture de conservation à la croisée des chemins en Afrique et à 657 Madagascar. Vertigo 9(3) 12. https://vertigo.revues.org/9290

658 Symondson, W.O.C, Glen, D.M., Wiltshire, C.W., Langdon, C.J., Liddell, J.E. 1996. Effects of 659 cultivation techniques and methods of straw disposal on predation by Pterostichus 
660 melanarius (Coleoptera: Carabidae) upon slugs (Gastropoda: Pulmonata) in an arable field.

661 J. Appl. Ecol. 33, 741 - 753. doi:10.2307/2404945

662 Sturz, A.V., Carter, M.R., Johnston, H.W., 1997. A review of plant disease, pathogen 663 interactions and microbial antagonism under conservation tillage in temperate humid 664 agriculture. Soil Tillage Res. 41-42, 169-189. doi:10.1016/S0167-1987(96)01095-1

665 Tilman, D., Cassman, K.G., Matson, P.A., Naylor, R., Polasky, S., 2002. Agricultural 666 sustainability and intensive production practices. Nature 418, 671-677. 667 doi:10.1038/nature01014

668 United Nations - Department for Policy Coordination and Sustainable Development, 1996. 669 Indicators of Sustainable Development, Frameworks and Methodologies, United Nations 670 New York.

671 Vian, J.F., Peigné, J., Chaussod, R., Estrade, J.R., 2009. Comparison of four tillage systems 672 in organic farming. Effect of soil structure modification and organic matter repartition on 673 microbial biomass and soil respiration. IOBC/WPRS Bulletin 42, 191-194. 


\section{Table captions}

Table 1: Methods for evaluating the basic criteria of the economic and social dimensions of the MASC model: QT - indicators based on quantitative and calculated data; QL - indicators based on expert evaluation through the use of qualitative information; ST - indicators based on a subtree design, using DEXi software to combine qualitative expertise and quantitative data through calculation. For these indicators, weights (expressed in \%) are assigned to the factors considered.

Table 2: Methods for evaluating basic criteria for the environmental dimension of the MASC model: QT - indicators based on quantitative and calculated data; QL - indicators based on expert evaluation through the use qualitative information; ST - indicators based on a subtree design, using DEXi software to combine qualitative expertise and quantitative data through calculation. For these indicators, weights (expressed in \%) are assigned to each of the factors considered.

Table 3: Simplified presentation of the cropping systems studied in each region. Each line of this table corresponds to the description of one of the 31 cropping systems assessed. A code is assigned to each cropping system to specify its affiliation a given type (DS: direct seeding, RT: reduced tillage, PL: frequent use of ploughing, LC: Low diversification of crop rotations, HC: High diversification of crop rotations). For the cultivated crops: AFA alfalfa, FAB faba bean, FES fescue, HP hemp, FF fibre flax, MAG grain maize, MAS silage maize, OR oilseed rape, SBEET sugarbeet, SOY soybean, SPEA spring pea, SUN sunflower, TRIT triticale, WB winter barley, WPEA winter pea, WW winter wheat. The cover crops are indicated in brackets: (Must.) mustard, (mgl) mixture of grass and legumes, (b.wheat) buckwheat, (fab) faba bean, (oat) oat, (rye) rye. For the origin of the observations: $F$ on-farm observations, $S$ for observations at experimental stations. 


\section{Figure captions}

Figure 1: Sustainability criteria information processing and aggregation in the MASC 2.0 decision tree. Numerical values in the decision tree displayed in red boxes represent the weights (expressed in \%) proposed by the designers of the MASC model.

Figure 2: Typology of the cropping systems defined by expertise to qualify the degree to which CA principles are implemented. DS: direct seeding, RT: reduced tillage, PL: frequent use of ploughing, LC: Low diversification of crop rotations, HC: High diversification of the crop rotations.

Figure 3: Mean score (and standard deviation), by cropping system type, for the most aggregated criterion (i.e. overall sustainability) and for the three dimensions of sustainability. Cropping system types characterised by a "Low diversification of crop rotations" are presented in light grey, and types with a "High diversification of crop rotations" are presented in dark grey.

Figure 4: Mean score (and standard deviation) by cropping system type for criteria in the economic branch of the MASC model. PL: Frequent use of ploughing, RT: reduced tillage, DS: direct seeding. Types characterised by a "Low diversification of crop rotations" are presented in light grey, and types with a "High diversification of crop rotations" are presented in dark grey.

Figure 5: Mean score (and standard deviation) by cropping system type, for the criteria in the social branch of the MASC model. PL: Frequent use of ploughing, RT: reduced tillage, DS: direct seeding. Cropping system types characterised by a "Low diversification of crop rotations" are presented in light grey, and types with a "High diversification of crop rotations" are presented in dark grey.

Figure 6: Mean score (and standard deviation), by cropping system type, for some of the criteria in the environmental branch of the MASC model. PL: Frequent use of ploughing, RT: reduced tillage, DS: direct seeding. Cropping system types characterised by a "Low diversification of crop rotations" are presented in light grey, and types with a "High diversification of crop rotations" are presented in dark grey. 
Figure 1

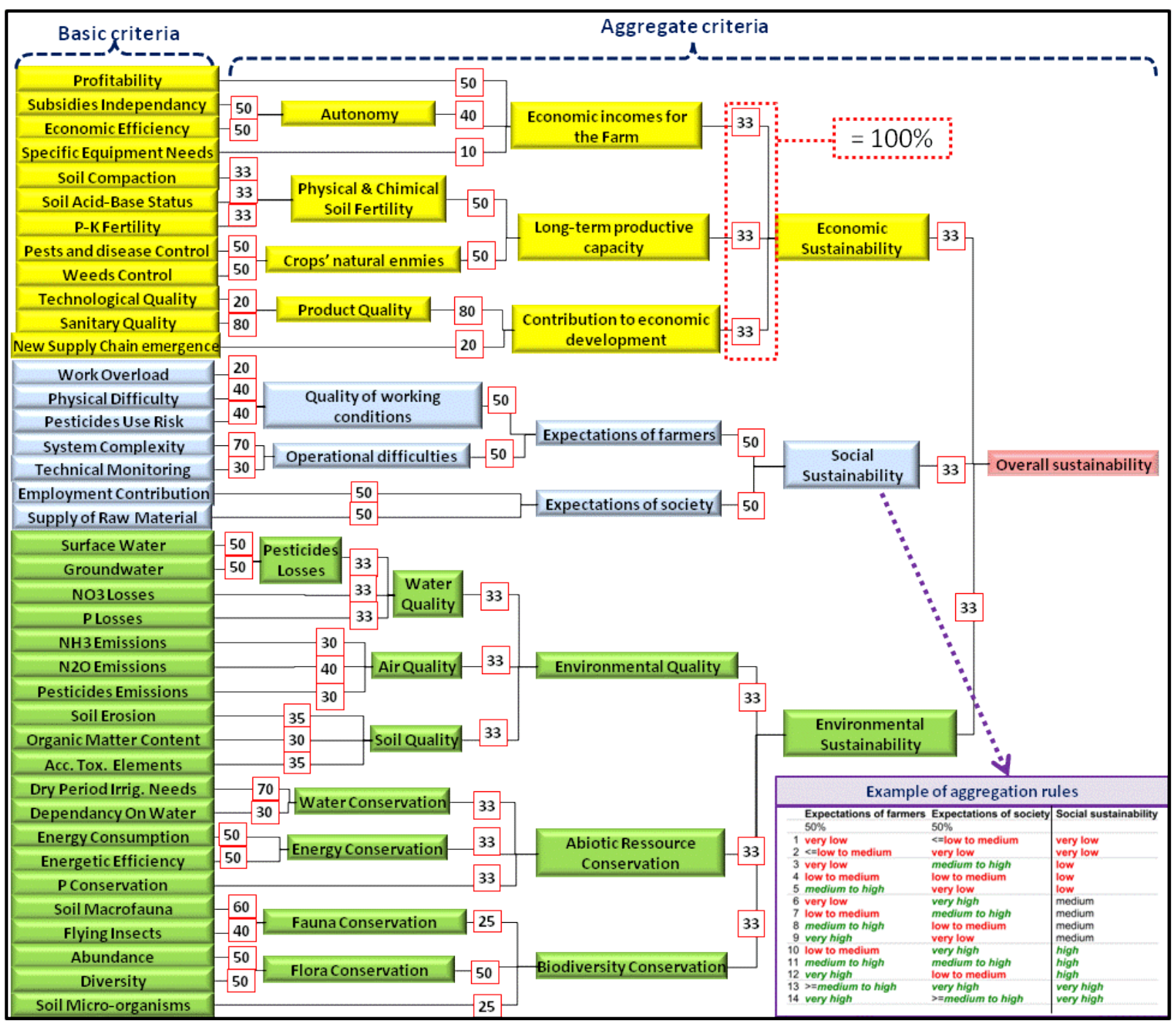



Figure 2

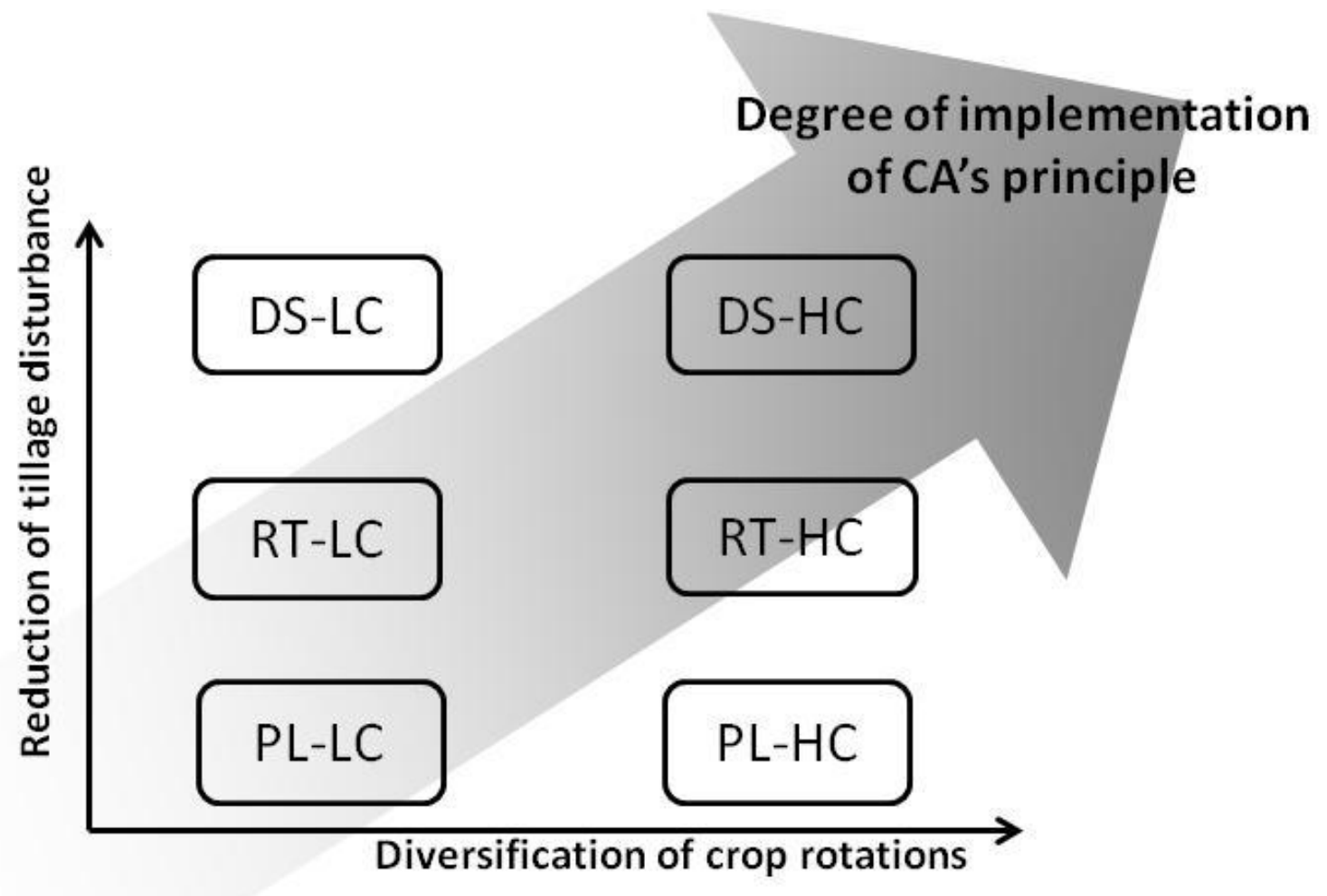


Figure 3

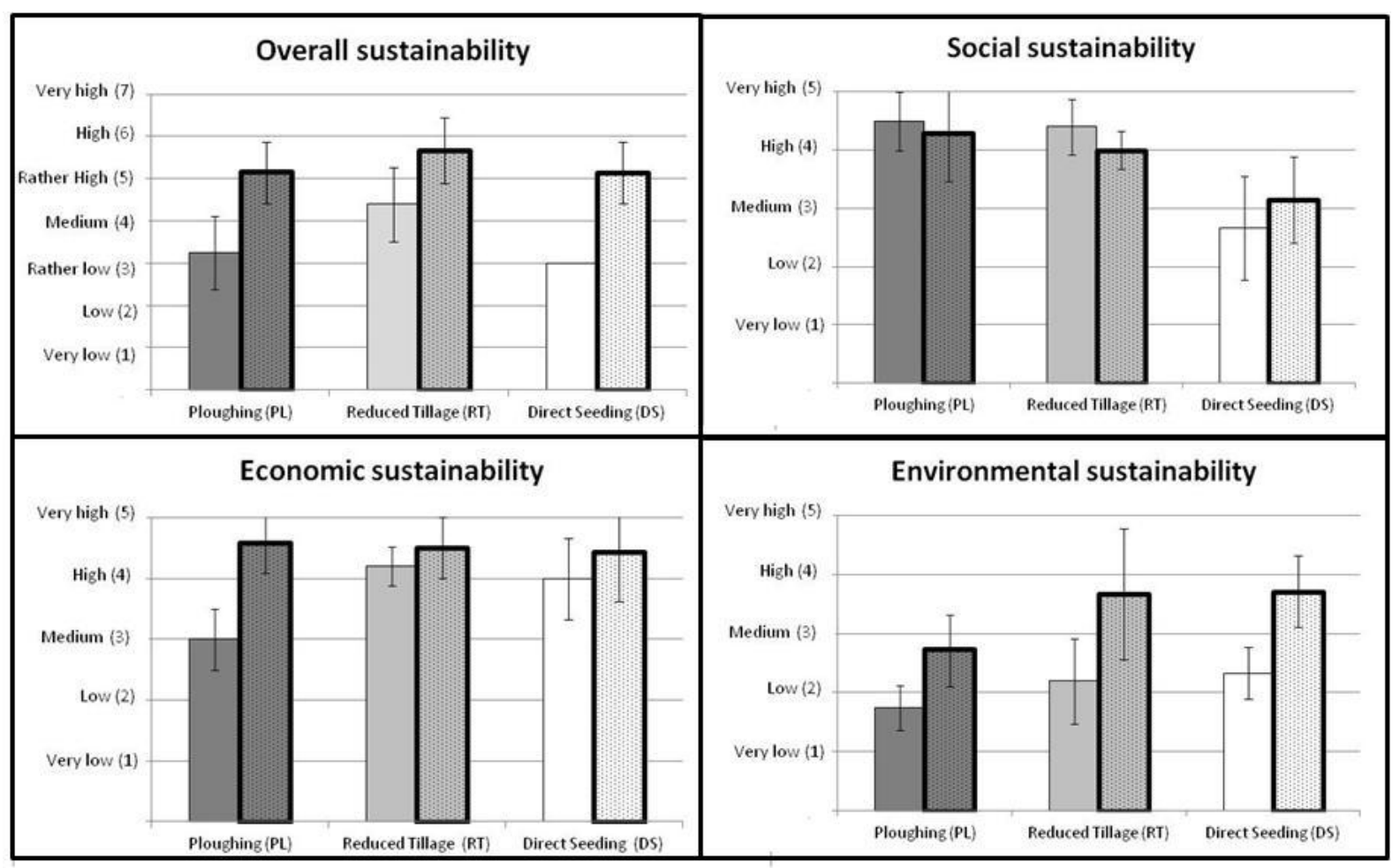


Click here to download Figure: Craheixetal_Figure 4.docx

Figure 4
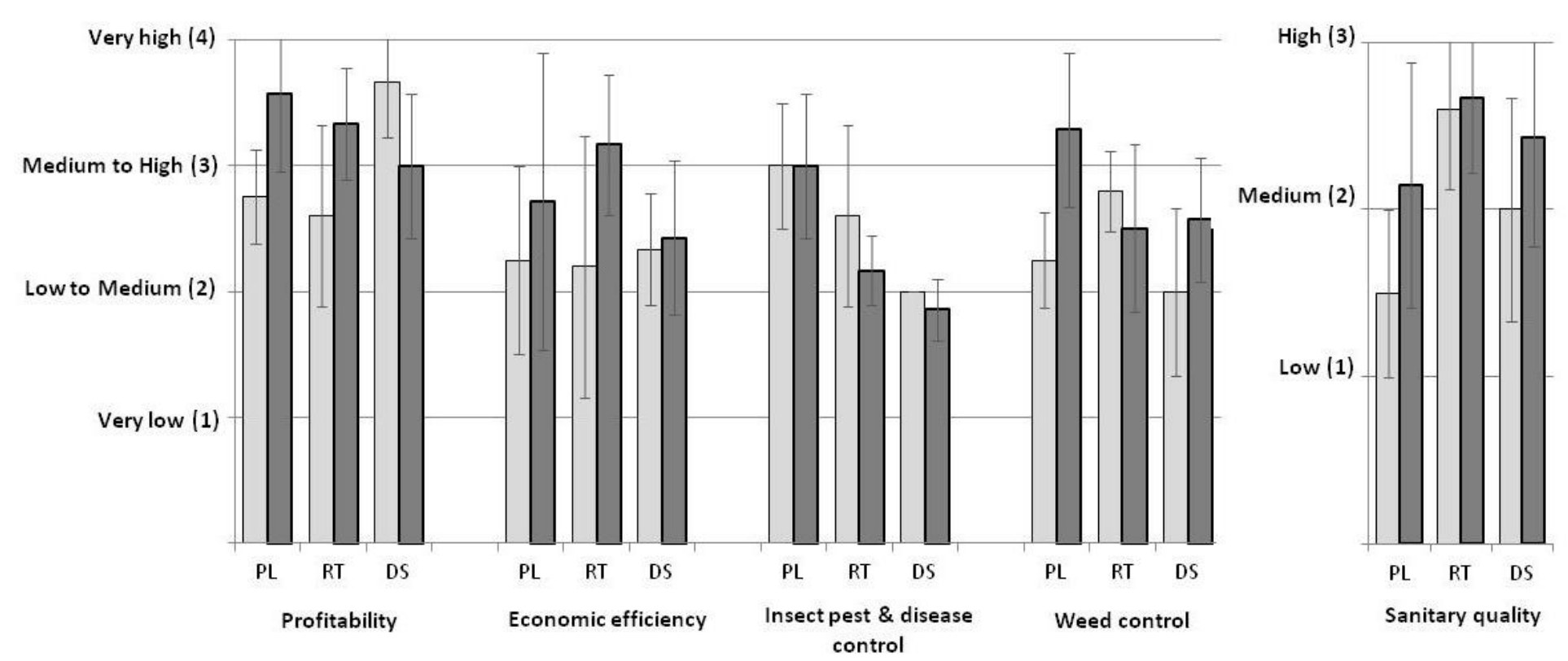
Click here to download Figure: Craheixetal_Figure 5.docx

Figure 5
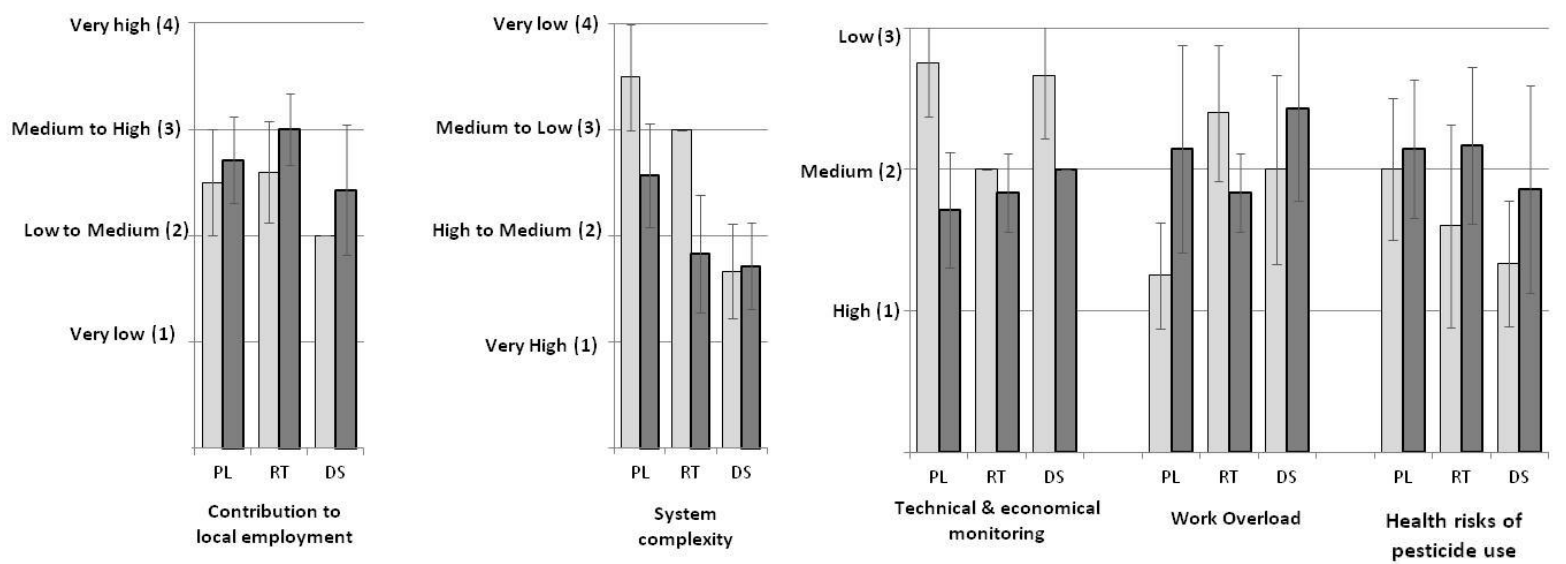
Click here to download Figure: Craheixetal_Figure 6.docx

Figure 6
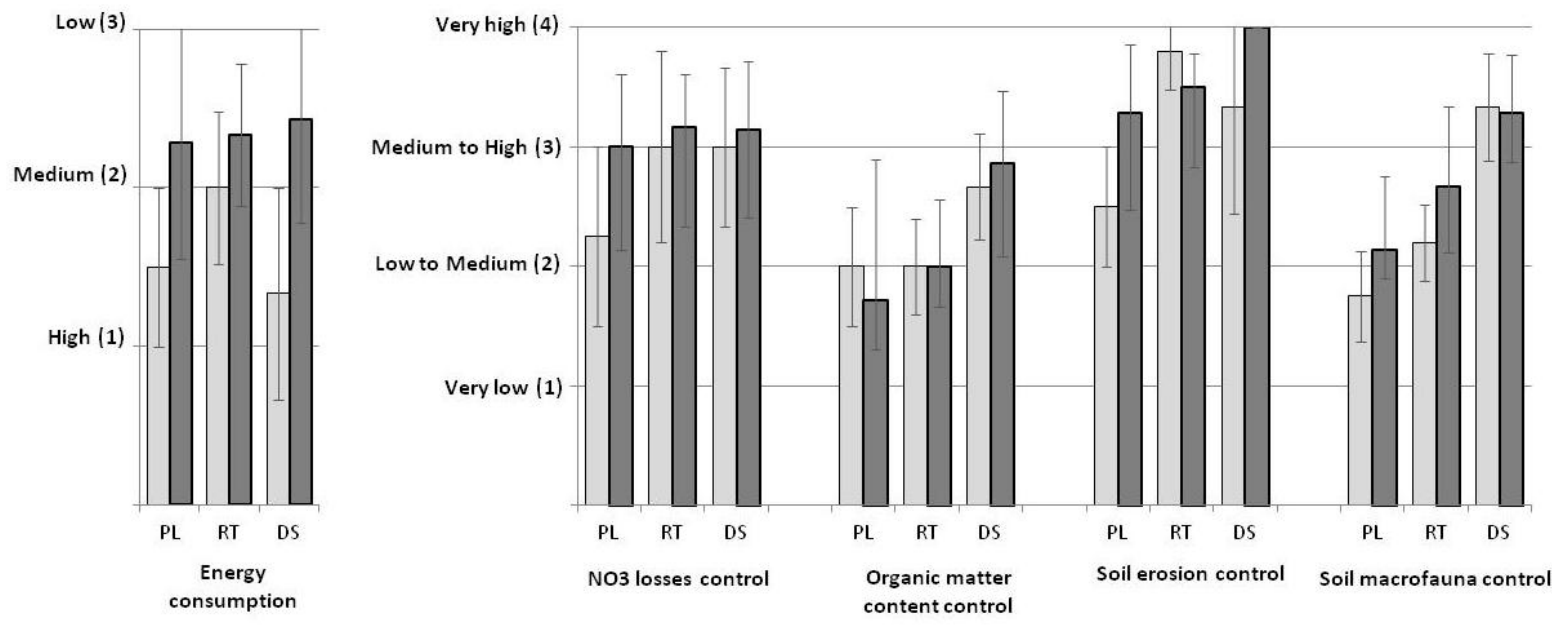
Table 1

\begin{tabular}{|c|c|c|c|}
\hline & Basic criteria & Mode & Reference methods or main factors considered \\
\hline \multirow{12}{*}{ 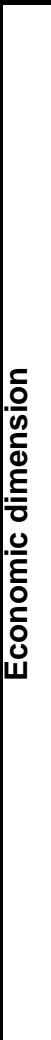 } & Profitability & QT & $\begin{array}{l}\text { Semi-net margin, considering subsidies and mechanical cost } \\
\left(€ . \text { ha }^{-1} \text {.year }{ }^{-1}\right) \text {. }\end{array}$ \\
\hline & Subsidies Independency & QT & Mean ratio of semi-net margin to subsidies $\left(\% \cdot\right.$ ha $^{-1} \cdot$ year $\left.^{-1}\right)$. \\
\hline & Economic efficiency & QT & Mean ratio of semi-net margin to operational costs $\left(\% \cdot\right.$ ha $^{-1}$.year $\left.{ }^{-1}\right)$. \\
\hline & Specific equipment needs & QL & Additional costs to purchase specific machinery. \\
\hline & Soil compaction & ST & $\begin{array}{l}\text { Regeneration factors (60\%): climate effects (13\%); tillage effects (13\%); } \\
\text { biological effects (13\%) / Damaging factors ( } 40 \%) \text { : harvest in wet climatic } \\
\text { conditions (60\%) specific equipment to reduce soil compaction }(40 \%) \text {. }\end{array}$ \\
\hline & Soil acid-base status & ST & $\begin{array}{l}\text { Initial soil pH (35\%); buffering capacity of soil (15\%); basic fertiliser effects } \\
(25 \%) \text {; effects of acidifying practices }(25 \%) \text {. }\end{array}$ \\
\hline & P-K fertility & ST & $\begin{array}{l}\text { Initial soil fertility (35\%); soil buffer capacity (15\%); nutrient balance (33\%); } \\
\text { organic matter recycling (16\%). }\end{array}$ \\
\hline & $\begin{array}{l}\text { Control of insect pests and } \\
\text { diseases }\end{array}$ & ST & $\begin{array}{l}\text { Diversity of the families of crops (50\%); management of harvest residues } \\
(30 \%) \text {; effects of genetic, chemical and biological control }(20 \%) \text {. }\end{array}$ \\
\hline & Weed control & ST & $\begin{array}{l}\text { Diversity of crop sowing dates (50\%); ploughing effect (20\%); effects of } \\
\text { mechanical, chemical and cover control }(30 \%) \text {. }\end{array}$ \\
\hline & Technological quality & QL & $\begin{array}{l}\text { Risk of failure to meet the level of quality required by the agro-food } \\
\text { production chain. }\end{array}$ \\
\hline & Sanitary quality & QT & $\begin{array}{l}\text { Mean, over the entire rotation, of annual indices describing the } \\
\text { contamination risk of cereals by mycotoxins (taking into account the } \\
\text { previous crop, the management of harvest residues and varietal } \\
\text { susceptibility). }\end{array}$ \\
\hline & New Supply Chain emergence & QT & Proportion, in the rotation, of crops marginally represented in the region. \\
\hline \multirow{7}{*}{ 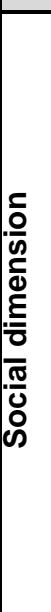 } & Workload distribution & QL & $\begin{array}{l}\text { Expertise concerning the distribution of the most time-consuming } \\
\text { interventions (e.g. ploughing, sowing, harvesting). }\end{array}$ \\
\hline & Physical difficulty & $\overline{Q L}$ & Expertise considering the physical difficulty of each crop intervention. \\
\hline & Pesticide use risk & QT & Annual mean of chemical interventions classified as toxic $\left(\right.$ ha $^{-1}$.year $\left.{ }^{-1}\right)$. \\
\hline & System complexity & QT & $\begin{array}{l}\text { Annual mean of indices defined with farms \& advisors to consider the main } \\
\text { difficulties in crop management (i.e. presence of cover crop, mechanical } \\
\text { weeding) (i. year }{ }^{-1} \text { ). }\end{array}$ \\
\hline & Technical monitoring & QL & $\begin{array}{l}\text { Estimation of the effort required by a farmer to keep up to date with } \\
\text { knowledge about the technical and economic environment of each crop } \\
\text { (number of different crops in the rotation). }\end{array}$ \\
\hline & Employment contribution & QT & Mean annual labour time (h. ha ${ }^{-1}$ year $\left.{ }^{-1}\right)$. \\
\hline & Supply of raw material & QT & $\begin{array}{l}\text { Mean difference between the observed yields of each crop and those } \\
\text { achieved in intensive production systems in the region }\left(\% . \text { ha }^{-1} . \text { year }^{-1}\right) \text {. }\end{array}$ \\
\hline
\end{tabular}


Table 2

\begin{tabular}{|c|c|c|c|}
\hline & Basic criteria & \multicolumn{2}{|r|}{ Mode Reference methods or main factors considered } \\
\hline \multirow{20}{*}{ 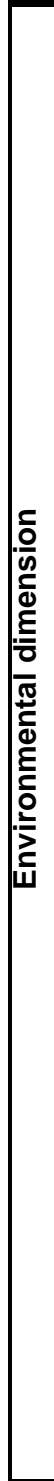 } & Pesticides (surface water) & QT & 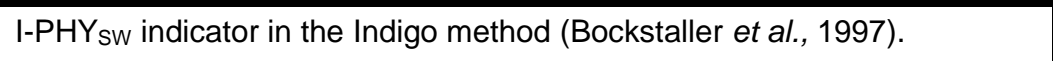 \\
\hline & Pesticides (ground water) & QT & I-PHYGW indicator in the Indigo method (Bockstaller et al., 1997). \\
\hline & $\mathrm{NO}_{3}$ Losses & QT & I-NO3 indicator in the Indigo method (Bockstaller et al., 1997). \\
\hline & Phosphorus losses & ST & $\begin{array}{l}\text { Initial soil phosphorus content (20\%), soil erosion (30\%), mean amount of } \\
\text { phosphorus provided (30\%) and method of incorporation }(20 \%) \text {. }\end{array}$ \\
\hline & $\mathrm{NH}_{3}$ emissions & QT & I-NH3 indicator in the Indigo method (Bockstaller et al., 1997). \\
\hline & $\mathrm{N}_{2} \mathrm{O}$ emissions & QT & I-NO2 indicator in the Indigo method (Bockstaller et al., 1997). \\
\hline & Pesticide emissions & QT & I-PHY air indicator in the Indigo method (Bockstaller et al., 1997). \\
\hline & Soil Erosion & ST & $\begin{array}{l}\text { Soil cover in period of risk (55\%); Tillage effects (35\%); Soil compaction } \\
(10 \%) .\end{array}$ \\
\hline & Organic matter content & QT & I-MO indicator in the Indigo method (Bockstaller et al.,1997). \\
\hline & $\begin{array}{l}\text { Accumulation of toxic. } \\
\text { elements }\end{array}$ & QL & $\begin{array}{l}\text { Expertise based on the presence/absence of acidification risks and } \\
\text { pollution with heavy metals or organic micropollutants. }\end{array}$ \\
\hline & Dry period irrigation needs & QT & Water consumption for irrigation during critical periods $\left(\mathrm{m}^{3} \cdot \mathrm{ha}^{-1} \cdot \mathrm{year}^{-1}\right)$. \\
\hline & Dependence on water & ST & $\begin{array}{l}\text { Crop water demands (50\%); Proportion of crop water demands covered by } \\
\text { irrigation }(50 \%) \text {. }\end{array}$ \\
\hline & Energy consumption & QT & I-EN indicator in the Indigo method (Bockstaller et al.,1997). \\
\hline & Energy efficiency & QT & $\begin{array}{l}\text { Mean ratio between energy consumption of each crop and energy } \\
\text { provided by harvested products }\left(\mathrm{Mj}^{-1} \cdot \mathrm{Mj}^{-1} / \mathrm{ha} / \text { year }\right) \text {. }\end{array}$ \\
\hline & Phosphorus conservation & QT & Mean phosphate rock consumption $\left(\mathrm{kg} \mathrm{P}_{2} \mathrm{O}_{5} \cdot\right.$ ha $^{-1}$.year $\left.{ }^{-1}\right)$ \\
\hline & Soil macrofauna & ST & $\begin{array}{l}\text { Tillage effects (40\%); Effects of added organic matter (35\%); TFLi: } \\
\text { Treatment Frequency Index (Gravesen, 2003) of all insecticides (25\%). }\end{array}$ \\
\hline & Flying insects & ST & $\begin{array}{l}\text { Diversity of the crop families (50\%); TFLi: Treatment Frequency Index } \\
\text { (Gravesen, 2003) of all insecticides (50\%). }\end{array}$ \\
\hline & Flora abundance & ST & Inverse of the result provided by the criterion "weed control". \\
\hline & Flora diversity & ST & $\begin{array}{l}\text { Diversity of sowing dates (50\%); use of broad-spectrum herbicides }(35 \%) \text {; } \\
\text { field margin management }(15 \%) \text {. }\end{array}$ \\
\hline & Soil micro-organisms & ST & $\begin{array}{l}\text { Diversity of crop families (25\%); Effects of added organic matter (50\%); } \\
\text { TFIt: Treatment Frequency Index (Gravesen, 2003) of all pesticides (25\%). }\end{array}$ \\
\hline
\end{tabular}


Table 3

\begin{tabular}{|c|c|c|c|c|c|}
\hline Type & Crop sequence & Region & Origin & Soil & $\begin{array}{c}\text { Frequency } \\
\text { of } \\
\text { ploughing }\end{array}$ \\
\hline \multirow{5}{*}{ PL-LC } & MAG-WW (Must.) & Haute-Normandie & $\mathrm{F}$ & Deep silty soil & $1 / 2$ \\
\hline & OR-WW-WPEA-WW-SB & Haute-Normandie & $\mathrm{F}$ & Deep silty soil & $2 / 5$ \\
\hline & OR-WW-WB & Champagne-Ardenne & $\mathrm{F}$ & Calcareous clay & $1 / 3$ \\
\hline & MAG-WW & Aquitaine & $\mathrm{F}$ & Sandy clay & $2 / 2$ \\
\hline & MAG-WW & Aquitaine & $\mathrm{F}$ & Sandy silt & $2 / 2$ \\
\hline \multirow{8}{*}{ PL-HC } & (Must.)SBEET-WW-(Must.)MAG-WW-(Must.)SB & \multirow{3}{*}{ Haute-Normandie } & $\mathrm{F}$ & \multirow{3}{*}{ Deep silty soil } & $5 / 5$ \\
\hline & OR-WW-FAB-WW-(Must.)MAG-WW & & $\mathrm{F}$ & & $2 / 6$ \\
\hline & OR-WW-HP-FES-OR-PEA-WW-WB & & $\mathrm{F}$ & & $8 / 8$ \\
\hline & OR-WW-(mgl)SB-(mgl)SUN-WW-(mgl)SB & \multirow{4}{*}{ Champagne-Ardenne } & $\mathrm{F}$ & Calcareous clay & $3 / 6$ \\
\hline & $\begin{array}{l}\text { OR-WW-(mgl)WB-(mgl)PEA-WW(mgl)SBEET- } \\
\text { SB-(mgl)SPEA-(mgl) }\end{array}$ & & $\mathrm{F}$ & \multirow{3}{*}{ Chalk } & $8 / 8$ \\
\hline & OR-WW-(mgl)SB-(mgl)-SBEET-WW-(mgl)SB- & & $\mathrm{F}$ & & $3 / 6$ \\
\hline & $\begin{array}{l}\text { OR-(mgl)-WB-SBEET-AFA-AFA-WW-(mgl)SB- } \\
(\mathrm{mgl}) \text { SPEA }\end{array}$ & & $\mathrm{F}$ & & $3 / 8$ \\
\hline & AFA-AFA-AFA-MAI-SOY-WW-(rye)SOY-WW & $\begin{array}{l}\text { Rhône-Alpes } \\
\text { (organic farming) }\end{array}$ & $S$ & Deep sandy silt & $6 / 8$ \\
\hline \multirow{3}{*}{ RT-LC } & OR-WW-SB-WW-FAB & Haute-Normandie & $\mathrm{F}$ & Deep silty soil & $1 / 5$ \\
\hline & OR-WW-WB-WPEA & Champagne -Ardenne & $\mathrm{F}$ & Calcareous clay & $1 / 4$ \\
\hline & OR-WW-WB & Centre & $\mathrm{S}$ & Calcareous clay & $0 / 3$ \\
\hline \multirow{5}{*}{ RT-HC } & FES-FES-WW-WB-FAB-WW-HP-WW-SB & Haute-Normandie & $\mathrm{F}$ & Deep silty soil & $0 / 9$ \\
\hline & $\begin{array}{l}\text { OR-WW-(Must.)FF-WW-WB-(Must.)SPEA-WW- } \\
\text { (Must.)SB }\end{array}$ & Haute-Normandie & $\mathrm{F}$ & Deep silty soil & $0 / 8$ \\
\hline & OR-WW-(must.)FAB-WW-(must.)SPEA-WW & Haute-Normandie & $\mathrm{F}$ & Deep silty soil & $0 / 6$ \\
\hline & AFA-AFA-AFA-MAI-SOY-WW-(rye)SOY-WW & $\begin{array}{c}\text { Rhône-Alpes } \\
\text { (organic farming) }\end{array}$ & $S$ & Deep sandy silt & $0 / 8$ \\
\hline & OR-WW-WB-SUN-WW & Centre & $S$ & Silt loam & $0 / 5$ \\
\hline \multirow{3}{*}{ DS-LC } & OR-WW & Franche-Comté & $\mathrm{F}$ & Calcareous clay & $0 / 2$ \\
\hline & OR-WW-WB & Centre & $S$ & Calcareous clay & $0 / 3$ \\
\hline & (mgl) MAG-WW & Aquitaine & $\mathrm{F}$ & Sandy silt & $0 / 2$ \\
\hline \multirow{7}{*}{ DS-HC } & OR-WW-(mgl)SOY & Franche-Comté & $\mathrm{F}$ & Calcareous clay & $0 / 3$ \\
\hline & OR-WW-(oat)SOY-WW & Franche-Comté & $\mathrm{F}$ & Calcareous clay & $0 / 4$ \\
\hline & OR-WW-(mgl)SB-(Must.)SPEA & Champagne -Ardenne & $\mathrm{F}$ & Chalk & $0 / 4$ \\
\hline & $\begin{array}{l}\text { AFA-AFA-AFA-MAI-(oat)SOY-WW-(rye)SOY- } \\
\text { WW }\end{array}$ & $\begin{array}{c}\text { Rhône-Alpes } \\
\text { (organic farming) } \\
\end{array}$ & S & Sandy clay & $0 / 8$ \\
\hline & OR-(fab)WW-WB-(rye)SUN-WW-(b.wheat)WPEA & Centre & S & Calcareous clay & $0 / 6$ \\
\hline & (mgl)MAG-(mgl)MAE-TRIT & Aquitaine & $\mathrm{F}$ & Sandy clay & $0 / 3$ \\
\hline & OR-WW-(mgl)SUN-WW-(mgl)FAB & Centre & S & Silt loam & $0 / 5$ \\
\hline
\end{tabular}

